\title{
Design and Analysis of Kinetic Energy Recovery System in Green Energy Vehicle
}

\author{
Deepak Yadav ${ }^{1}$, Priyal. R. Sawarkar ${ }^{2}$ \\ ${ }^{1,2}$ D. Y Patil College of Engineering, SPPU, Akurdi, Pune 411044, India
}

\begin{abstract}
Kinetic Energy Recovery System (KERS) is a system for recovering the moving vehicle's kinetic energy under braking and use it for accelerating the vehicle. When riding bicycle, muscular energy through peddling is converted into kinetic energy, during braking this kinetic energy is lost. We are recovering this kinetic energy by using Motor Generator Unit (MGU), which engage with the driving wheel during braking and generate power which can be stored in power banks. This energy can be reuse to boost our vehicle. In this way we can save the energy which was prior wasted in braking. This can be implement in bicycles, two/four wheelers motor vehicles.
\end{abstract}

Keywords: KERS, Regenerative Braking, Ultra-capacitor power storage, Electronic KERS

\section{Introduction}

Kinetic Energy Recovery System (KERS) is a device for recovering kinetic energy of moving vehicle during deceleration or braking, storing this energy in power banks like flywheel, ultra-capacitors, batteries etc. depends on type of KERS system used. This stored energy is again releases back to the drivetrain of the vehicle, providing a power boost to the driver when needed. For driver he has two power sources at disposal, one of them is main engine while the other is KERS. Kinetic energy recovery system (KERS) store energy when brakes are applied which is going to waste anyhow as it will be converted into thermal energy when brake shoes rub with rim and dissipated in atmosphere. In Green energy vehicles (bicycles) muscular energy through pushing of paddle is converted into bicycle's kinetic energy. Energy which is produced through muscular push of paddle is quite less and if this energy is wasted it will add to more muscular power required to push the bicycle. Hence there should be need of saving this energy. bicycles with KERS installed are able to harness this energy and also assists in braking. KERS are categorised into two types i.e. Electrical and Mechanical. The main difference between them is the in which they convert energy. In electrical KERS Motor generator unit (MGU) is used. During braking generator engage with driving wheel and generate power which can be stored in power banks, when extra power is needed we can deliver it through motor. In case of mechanical KERS kinetic energy of vehicle is stored in flywheels. In our model we have use electrical KERS.

\section{KERS for Bicycle Contruction}

During designing KERS for bicycle the fundamental thought in our mind was we need to save as much as energy possible. For that we needed a well setup or prototype.

\subsection{Design Requirement}

- It should store energy while braking

This is the soul requirement and overall objective of the device.
- It should deliver energy back to the driveline instantly when required

Once the energy is stored in power banks there should be simplified channel through which it can be transferred to the driveline.

- Easy installation on bicycle

This is one of the most difficult constraint to be achieved because we are dealing with very limited spacing.

- Light weight

Since we are using bicycle which is driven by driver using muscular power. Every extra pound of weight increases driver effort.

- Inexpensive and affordable

Product should be economic and desirable.

Safe to use and environmentally friendly

Safety is the primary requirement.

- Reliable

It is important to have product reliable, so that customer can trust on it.

- Controlling ease

It is expected that the product must be easy to control.

\subsection{Requirements}

- Chain sprocket set

- Steel shaft

- Milled Bakelite disc (for engagement/disengagement)

- Motor generator unit(MGU)

- Ultra-capacitor (500 Farad)

\subsection{Fabrication}

We have used a DC motor(500RPM) which will act as prime mover (peddling in case of bicycle). It is connected to a shaft with sprocket installed on shaft. Through chain drive this shaft is connected to the rear shaft which is the main driving wheel. This rear shaft has Bakelite disc on its one end. Coincide to this shaft we have Motor generator unit which had Bakelite disc like the other shaft. During braking MGU engage with rear shaft through Bakelite disc since they have high coefficient of friction and also they are milled for positive displacement. This will decelerate the bicycle along 


\section{International Journal of Science and Research (IJSR) \\ ISSN (Online): 2319-7064 \\ Index Copernicus Value (2013): 6.14 | Impact Factor (2015): 6.391}

with generate electricity which is stored in Ultra-capacitors. During ideal time MGU unit is in disengage position. In case we need temporary boost in bicycle we can again engage MGU with rear shaft which will deliver power instantly as Ultra-capacitors have high power density.

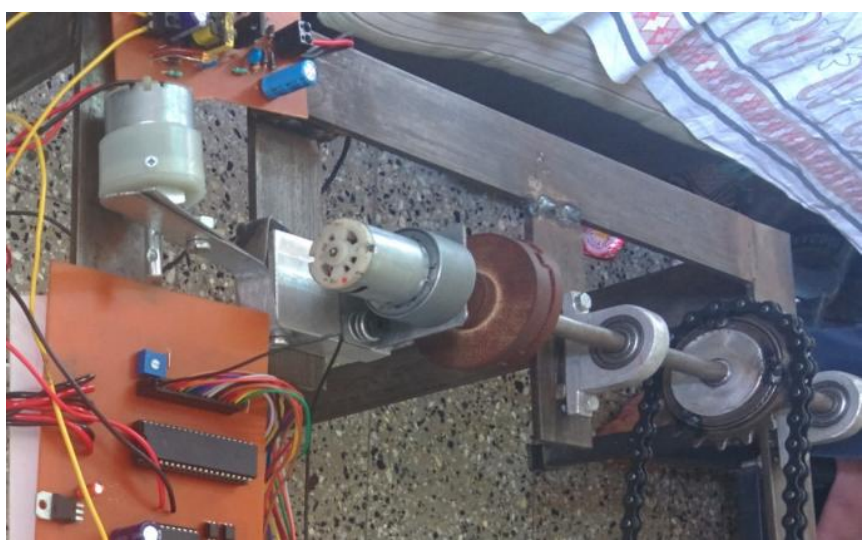

Figure 1: MGU

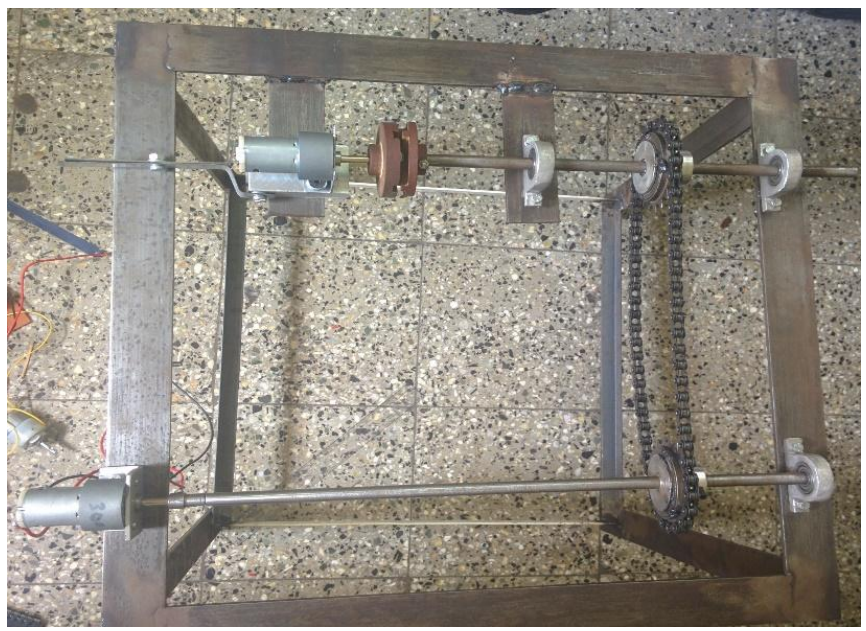

Figure 2: FRAME

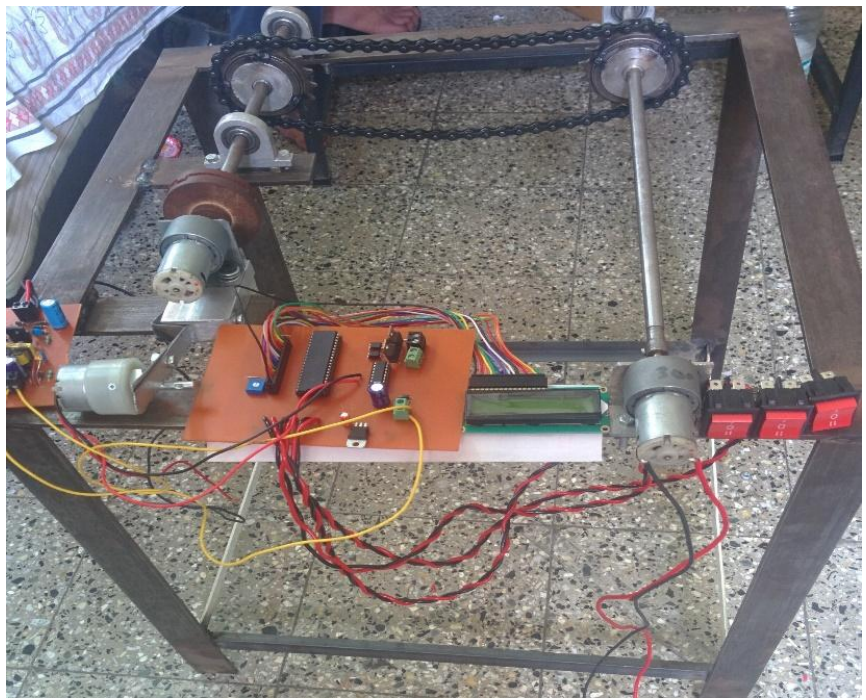

Figure 3: Detailed Prototype

\section{KERS Bicycle Working}

Rear wheel of bicycle is connected to the Motor generator unit (MGU) through Oldham coupling for positive displacement. When speed reduction is required and brakes are pressed MGU engage with the rear wheel and speed of bicycle is decreased. Thus a regenerative braking is achieved. Generator engage with rear wheel generate electricity which is stored in Ultra capacitors. In some cases, when brakes are to be applied fully Clutch engagement along with conventional braking is done. Now when we ride the bicycle we can reuse the stored energy in Ultra capacitor to boost the bicycle which can reduce overall pedaling by 10 per cent (theoretically). Also situation arises like coming down the hill, traffic jam where we are not intending to apply brake but have to apply, for such cases we can apply this smart braking system. This would decelerate the bicycle and also generate electricity which can be later used to boost the bicycle in normal riding and distance that can be covered by pedaling can be improved.

In case of traffic jams we are compelled to apply brakes to reduce the speed of bicycle. This energy is going to waste due to speed reduction and we can store this energy by engagement of MGU with rear wheel (KERS). When MGU is engage with rear wheel at that time during initial engage generator consumes energy which is being stored in the Ultra capacitors which results in speed reduction and eventually braking. This stored energy can be used anytime to accelerate the bicycle. While riding downhill we always use braking for slowing down bicycle. This is the best possible case where we can store maximum amount of energy in ultra-capacitors. MGU can be engage for the complete downhill ride, and at flat road we need not to peddle the bicycle this job is done by motor unit, this is the beauty of KERS. During long distance driving engagement can be done full time which decreases net pedaling effort. It is expected that pedaling power can be reduced by per cent. Although we have concentrate only on Green Energy Vehicle but our model is interdisciplinary and can be used in bicycles, 2/3/4 wheeler automobiles etc.

\section{Results}

\subsection{Limitation of flywheel in mechanical KERS}

- They are quite big in size, hence required large space for setup. This increases overall size of system.

- They are quite heavy and they increase overall weight of system. Which end up decreasing system efficiency.

- Energy stored in flywheels are temporary as it degrades with time that's why it can't be used any time. Energy stored in flywheel should be used as soon as possible for complete utilization.

\subsection{Difference between Ultra-Capacitors And Battries}

A few years earlier batteries were the best mode of storing power. But advances in technology over last few decades rise of different power sources takes place. One of them is Ultra-capacitors. Batteries store energy in a chemical reaction so they have inherent limitation in power density and charging discharging. If we need some amount of power in a range of time batteries are suited. But we need power in very short time means we need high power density for KERS. So, Ultra capacitor is the best way of storing power.

\section{Volume 5 Issue 6, June 2016}

www.ijsr.net 


\section{International Journal of Science and Research (IJSR) \\ ISSN (Online): 2319-7064}

Index Copernicus Value (2013): 6.14 | Impact Factor (2015): 6.391

Table 1: Difference between Battery and Ultra-capacitor

\begin{tabular}{|c|c|c|}
\hline Available Performance & $\begin{array}{c}\text { Lead Acid } \\
\text { Battery }\end{array}$ & Ultra-capacitor \\
\hline Charge Time & 1 To 5 hrs & 0.3 to $30 \mathrm{sec}$ \\
\hline Discharge Time & 0.3 to $3 \mathrm{hrs}$ & 0.3 to $30 \mathrm{sec}$ \\
\hline Energy (Wh/kg) & 10 to 100 & 1 to 10 \\
\hline Cycle Life & $<1000$ & $>500,000$ \\
\hline Specific Power (W/kg) & $<1000$ & $<10,000$ \\
\hline Charge/Discharge Efficiency & 0.7 to 0.85 & 0.85 to 0.98 \\
\hline Operating Temperature & -20 to $100{ }^{\circ} \mathrm{C}$ & -40 to $65^{\circ} \mathrm{C}$ \\
\hline
\end{tabular}

\subsection{Advantages of Ultra-Capacitors}

- They can charge and discharge much faster than batteries,

- They can use millions of times without degrading,

- They have little or no resistance and work efficiency is close to 100 per cent,

- They are significantly lighter than batteries,

- They don't contain harmful chemicals or toxic metals,

- They charge almost instantly,

- They have very high power to weight ratio then lithium ion batteries.

\section{Conclusion}

KERS system used in vehicles satisfies the purpose of saving a part of energy which was previously lost in braking. They are proved efficient as compared to the conventional braking systems. Our model is interdisciplinary and it can be used in all type of automobiles. The use of such more efficient systems lead to huge saving in the economy of any country. Thus, by using KERS installed vehicles we can save fossil fuels up to certain extent, and also we can also promote using Green vehicles (when KERS used in bicycles). We can decrease peddling effort by 10 per cent in bicycle by using KERS (as per result we get from prototype).

Here we are concluding that the topic KERS got a wide scope in the field of engineering to minimize loss in energy. Here we want to implement KERS in Green energy vehicle. Still different losses like friction are to be reduced and calculation has to be done with sophistication.

\section{References}

[1] Regenerative Braking for an Electric Vehicle Using Ultra capacitors and a Buck-Boost Converter by Juan W. Dixon, Micah Ortúzar and Eduardo Wiechmann, Department of Electrical Engineering, Catholic University of Chile, Santiago Conference 2014.

[2] KERS by means of flywheel energy storage, Cibulka J ADVANCED ENGINEERING 3(2009)1, ISSN 18465900.

[3] Comparative Study on Various KERS by Radhika Kapoor, C. Mallika Parveen, Member, IAENG, Proceedings of the World Congress on Engineering 2013 Vol III, WCE 2013, July 3 - 5, 2013, London, U.K.

[4] Design and analysis of KERS in bicycle by S Menon, Sooraj M, Sanjay Mohan, Rino Disney, S Sukumaran International Journal of Innovative Research in Science, Engineering and Technology Vol-2, Issue-8, August 2013.
[5] KERS by Pottabattini Naveen, Mamidi ranga rao, Novle Krishna, Aashish ambekar, Monica naga Sai latchireddy International Journal of Scientific \& Engineering Research, Volume 5, Issue 1, January-2014 1860 ISSN 2229-5518.

[6] KERS using Spring by Mayuresh Thombre, Prajyot Borkar, Mangirish Bhobe, World Academy of Science, Engineering and Technology International Journal of Mechanical, Aerospace, Industrial, Mechatronic and Manufacturing Engineering Vol:8, No:4, 2014.

\section{Author Profile}

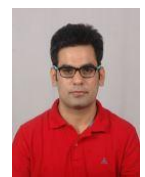

Deepak Yadav is currently pursuing his B.E in Mechanical Engineering from D.Y Patil College of Engineering, Akurdi. He was the member of college BAJA team and secured second rank at International level. 